\title{
Les Bières flottantes des négriers, un discours non prononcé sur l'abolition de la traite des Noirs
}

\section{Serge Bianchi}

\section{(2) OpenEdition \\ 1 Journals}

\section{Édition électronique}

URL : https://journals.openedition.org/ahrf/1134

DOI : 10.4000/ahrf.1134

ISSN : 1952-403X

Éditeur :

Armand Colin, Société des études robespierristes

\section{Édition imprimée}

Date de publication : 1 septembre 2001

Pagination : 126-127

ISSN : 0003-4436

\section{Référence électronique}

Serge Bianchi, «Les Bières flottantes des négriers, un discours non prononcé sur l'abolition de la traite des Noirs ", Annales historiques de la Révolution française [En ligne], 325 I juillet-septembre 2001, mis en ligne le 10 avril 2006, consulté le 23 avril 2022. URL : http://journals.openedition.org/ahrf/1134 ; DOI : https://doi.org/10.4000/ahrf.1134

\section{Ce document a été généré automatiquement le 23 avril 2022}

Tous droits réservés 


\title{
Les Bières flottantes des négriers, un discours non prononcé sur l'abolition de la traite des Noirs
}

\author{
Serge Bianchi
}

\section{RÉFÉRENCE}

Les Bières flottantes des négriers, un discours non prononcé sur l'abolition de la traite des Noirs, Publication de l'université de Saint-Étienne, 1999, 159 pages, présenté et annoté par Marcel Dorigny.

1 Sous le titre évocateur des «bières_flottantes» désignant les navires négriers pratiquant la traite à la fin du XvIII ${ }^{\mathrm{e}}$ siècle, Marcel Dorigny publie un discours de Mirabeau à la fois énigmatique et mythique. Prononcé de source sûre au Club des Jacobins le 1ermars 1790, il devait être lu à la séance de la Constituante du 3 mars. Mais pour des raisons à mieux définir, il ne fut ni prononcé, ni publié, avant les années 1830 ! Comme ce texte n'a laissé que peu de traces dans les documents officiels de l'époque (la presse, les réactions) on peut s'interroger sur l'opportunité d'une telle publication, en terme d'historiographie. Mais la simple lecture du discours reconstitué (avec patience) et des commentaires l'accompagnant permet de dégager plusieurs centres d'intérêt majeurs, à la réserve près d'un texte de Victor Hugo, peu relié au problème central de la traite. La présentation faite en 1835 par Lucas de Montigny complète de façon heureuse les éclairages apportés par Marcel Dorigny, spécialiste reconnu des questions abordées dans son discours par le tribun.

2 Le discours attire d'abord l'attention sur la connaissance que Mirabeau, ou ses collaborateurs possèdent sur une question où se sont plutôt illustrées des personnalités comme l'abbé Grégoire, ou Condorcet, porte-parole du courant abolitionniste. Mirabeau dénonce l'inhumanité de la traite et la nécessité d'une abolition rapide. Les propositions comme les analyses puisent dans les avancées du courant abolitionniste de 
la fin des années 1780, de Clarkson (Essai sur l'esclavage) aux Amis des Noirs en passant par Wilberforce. Mirabeau se réfère à tous ces plaidoyer, proposant même in fine une abolition conjointe en France et dans les îles britanniques! Il connait bien la situation de Saint-Domingue, faisant preuve d'érudition, tant sur les données démographiques que sur le commerce colonial, dont il n'oublie aucun chiffre. Son discours ne brille toutefois pas par son originalité. Comme l'abbé Raynal, il part du discours prêté aux partisans de la traite pour réfuter une à une leurs propositions: l'histoire, les intérêts britanniques, les arguments d'humanité relative, le parallèle avec la misère contemporaine des paysans, autant d'arguments balayés par une éloquence véhémente et passionnée. Le discours fait mouche lorsqu'il évoque les problèmes du trafic, la mortalité des esclaves, les humiliations subies. Mais il replace ces évolutions dans le cadre général de la colonisation, qui n'a pu qu'aggraver les vices constitutifs de l'état d'Africain et pose la question des responsabilités des États européens, écartant par là même la perspective d'une abolition immédiate de l'esclavage.

3 Aux arguments abolitionnistes classiques, Mirabeau ajoute la vision de l'économie politique dominante, marquée par la pensée des physiocrates (Baudeau) et par les réflexions d'Adam Smith. La libération des esclaves se fera par leur remplacement progressif par des petits propriétaires de couleur et par des salariés, dont la productivité sera supérieure. Sa réfutation des profits du commerce lié à la traite, comparés aux profits britanniques, se caractérise par la technicité érudite des décomptes, si différente des calculs des membres du club Massiac ou de l'abbé Maury. Le mélange de «cris_du_cœur» (Yves Bénot) et de la vision économiste caractérise ainsi le discours du tribun.

4 Mais il est adapté à la situation «explosive» de Saint-Domingue, dans le contexte si prégnant de la marche de la Révolution. Les inégalités structurelles de la société (le poids presque égal aux créoles des gens de couleur libre) rendent plus choquantes les contradictions par rapport à la Déclaration des droits. Mirabeau demande, comme les Amis des Noirs, des droits équivalents en matière de représentation politique, dépassant le simple exercice du vote et de la garde nationale. Il a tendance à idéaliser la fin de la féodalité en métropole au moment du décret sur le rachat des redevances, et conserve dans toute l'argumentation le souci politique de ne pas provoquer de rupture brutale, susceptible de léser gravement l'une des parties en présence dans l'île. Ses conclusions sont ainsi décevantes à l'égard des prémices, dans l'appel au souverain britannique et dans la mise sur pied d'un... comité «pour_préparer_la_liberté», alors qu'on attendrait la suppression de la traite et des primes aux négriers.

5 Car l'énigme demeure dans la non-prononciation du discours à l'Assemblée. Les hypothèses de Marcel Dorigny, éclairant le contexte politique du moment, sont particulièrement suggestives. Entre un discours aux Jacobins le 1er mars (peu analysé dans la presse) et le 3 (discours attendu à la Constituante), s'est créé un comité colonial où les représentants des intérêts des planteurs sont majoritaires. Le compromis en préparation au sein de la société de 1789 entre Mirabeau et ces partisans (Moreau de Saint-Méry) ne fait guère de doute. Le tribun va prendre ses distances avec les Amis des Noirs (Brissot), au point que le texte ne sera même pas imprimé, et que cette face de l'activité de Mirabeau sera oubliée par l'historiographie. Le réquisitoire de Mirabeau est intéressant par la confusion des genres entre le discours philosophique, la mise en perspective politique, la prophétie sur l'avenir de l'île, certains accents caractéristiques de l'éloquence du tribun. La révolte des esclaves suivra d'assez près le transfert de la 
dépouille de Mirabeau au Panthéon, sans que ce dernier rejoigne les grands abolitionnistes de l'époque. La publication de ce discours inédit et rentré met en lumière les qualités et les contradictions d'une personnalité politique complexe, l'ampleur des pressions du «parti_des_planteurs», l'inadéquation des analyses et des solutions proposées. Elle ajoute une pièce de poids à l'ensemble des projets et des discours préparés et non prononcés, comme le plan d'éducation de Condorcet en avril 1792, et tant d'autres discours utopiques, balayés par les réalités politiques du moment... 